\title{
PERENCANAAN KESEIMBANGAN LINI (LINE BALANCING) UNTUK MENINGKATKAN EFISIENSI LINTASAN KERJA PERKAITAN ELEVATOR PADA PT HYUNDAI ELEVATOR INDONESIA
}

\author{
HERMANTO \\ Prodi Teknik Industri Fakultas Teknik dan Ilmu Komputer \\ Universitas Indraprasta PGRI Jakarta \\ Email:hers3sm@gmail.com,hermanto@unindra.ac.id
}

\begin{abstract}
The aim of the study was to improve the line balance at the elevator assembly of PT Hyundai Elevator Indonesia by using the line balancing method. One method used is the method of Reduced Positional Weights Method (RPW). In this study the researchers proposed improving line balance to improve track efficiency elevator assembly at PT Hyundai Elevator Indonesia. After the researchers do data processing using line balancing method proposed, the author can draw conclusions from the line balancing method of calculation with using the kill-bridge Weston heuristic $(K W H)$ method, with a balace delay of $4 \%$, a smoothing index of 35 minutes and efficiency of $96 \%$ so that the results can be used as line balance planning to improve efficiency work at PT Hyundai Elevator Indonesia.
\end{abstract}

Keywords: Line balance, RPW-KWH method, Assembly Work Path efficiency.

\begin{abstract}
ABSTRAK
Tujuan penelitian adalah untuk memperbaiki keseimbangan lini pada perakitan elevator PT Hyundai Elevator Indonesia dengan menggunakan metode line balancing. Satu metode yang digunakan yaitu metode Metode Rangked Positional Weights (RPW),. Pada penelitian ini peneliti mengusulkan perbaikan keseimbangan lini untuk meningkatkan efisiensi lintasan pada perakitan elevator di PT Hyundai Elevator Indonesia. Setelah peneliti melakukan pengolahan data dengan menggunakan metode line balancing yang diusulkan, penulis dapat menarik kesimpulan dari metode line balancing perhitungan dengan menggunakan metode kill - bridge Weston heuristic $(\mathrm{KWH})$, dengan balace delay sebesar 4\%, smoothing indeks 35 menit dan efisiensinya $96 \%$ Sehingga hasil yang di dapat bisa sebagai perencanaan keseimbangan lini untuk meningkatkan efisiensi kerja pada PT Hyundai Elevator Indonesia.
\end{abstract}

Kata Kunci: Keseimbangan Lini, Metode RPW-KWH, Efisiensi Lintasan Kerja Perakitan.

\section{PENDAHULUAN}

Perusahaan PT. Hyundai elevator Indonesia merupakan perusahaan yang bergerak di bidang manufaktur. Perusahaan Hyundai elevator Indonesia melayani dalam perakitan elevator yang sesuai dengan permintaan pelanggan. Perusahaan elevator ini merakit dalam bentuk yang bervariasi sesuai dengan keinginan pelanggan. Pada perusahaan ini perakitan elevator umumya digunakan pada perusahaan atau gedung bertingkat dan gedung besar. Perakitan elevator ini membutuhkan waktu dalam dua hari hal ini dikarenakan komponen pada perakitan elevator ini terlalu banyak dan adanya lini perakitan yang tidak memadai dengan proses perakitan elevator 
menjadi lebih lama dan menyebabkan terjadinya penumpukan perakitan elevator pada perusahaan ini.

Perakitan elevator pada perusahaan PT Hyundai elevator Indonesia juga merakit elevator dalam bentuk yang bervariasi sehingga banyak keterlambatan dalam perakitan elevator menyebabkan kerugian terhadap perusahaan karena waktu yang telah ditentukan tidak dapat terpenuhi, serta komponen yang dibutuhkan bervariasi dalam proses perakitan elevator. Efiesiensi kerja pada perakitan elevator yang telalu lama menyebabkan ketidak seimbangan antara produk perakitan elevator dengan lintasan perakitan. Penumpukan dan pengangguran dalam proses perakitan menjadi lebih besar. Sehingga dalam hal ini perlu dilakukan perbaikan keseimbangan lintasan perkitan dengan menggunakan line balancing.

\section{METODOLOGI PENELITIAN}

Metode Penelitian yang digunakan dalam keseimbangan lintasan perakitan pembuatan elevator adalah Metode Rangked Positional Weights (RPW), berdasarkan dari pembobotan terbesar. Teknik yang digunakan dalam menganalisis data adalah dengan beracuan dari efisiensi lintasan serta balance delay karena dengan adanya efisiensi lintasanya dapat diketahui tingkat penggunaan lintasan pada perakitan, serta mengetahui dari delay time nya agar waktu kelonggaran dalam proses perakitan komponen elevator menjadi berkurang. Serta smoothing indeks yang digunakan dalam keseimbangan lintasan juga berkurang.

\section{PENGOLAHAN DAN ANALISIS DATA}

Tabel 4.1 Data Waktu Siklus Dari Perakitan Elevator

\begin{tabular}{|c|l|c|}
\hline No & \multicolumn{1}{|c|}{ Elemen-Elemen } & Waktu (mnt) \\
\hline 1 & Perakitan Motor Dengan Machine Beam. & 19.53 \\
\hline 2 & $\begin{array}{l}\text { Perakitan Motor Dengan Machine Beam } \\
\text { dan Traction Machine. }\end{array}$ & 29.47 \\
\hline 3 & $\begin{array}{l}\text { Perakitan motor Dengan Machine Beam, } \\
\text { Tractotion, Dan Deflector sheave. }\end{array}$ & 28.47 \\
\hline 4 & $\begin{array}{l}\text { Perakitan motor Dengan Machine Beam, } \\
\text { Tractotion, Deflector Sheave, Ctrl Pnl. }\end{array}$ & 17.53 \\
\hline 5 & $\begin{array}{l}\text { Perakitan mtr Dgn Mc Beam, Tractotion, } \\
\text { Defl S, Ctrl Pnl , Overspeed Governer. }\end{array}$ & 27.53 \\
\hline 6 & $\begin{array}{l}\text { Perakitan Car Door Dengan Door safety } \\
\text { device. }\end{array}$ & 48.47 \\
\hline 7 & $\begin{array}{l}\text { Perakitan car Door Dengan Door safety } \\
\text { device dan Door operator. }\end{array}$ & 19.47 \\
\hline 8 & $\begin{array}{l}\text { Perakitan Bagian Atas dan Lift Dengan } \\
\text { Car Guide Rail. }\end{array}$ & 39.53 \\
\hline 9 & $\begin{array}{l}\text { Perakitan Bagian Atas dan Lift Dengan } \\
\text { Car Guide Roller. }\end{array}$ & 14.47 \\
\hline 10 & $\begin{array}{l}\text { Perakitan Counterweight dan } \\
\text { counterweight guid rail. }\end{array}$ & 15.47 \\
\hline 11 & $\begin{array}{l}\text { Perakitan Counterweight, counterweight } \\
\text { guid rail dan Guid Roller. }\end{array}$ & 18.53 \\
\hline 12 & $\begin{array}{l}\text { Perakitan lift dan counterweight dengan } \\
\text { Bagian Atas. }\end{array}$ & 17.47 \\
\hline 13 & $\begin{array}{l}\text { Perakitan lift dan counterweight dengan } \\
\text { Car Guide Rail Bracket. }\end{array}$ & 20.53 \\
\hline 14 & Produk lift & 0.00 \\
\hline & \multicolumn{1}{|c|}{ ToTAL } \\
\hline
\end{tabular}

\section{Pengolahan Data}

Pada pengolahan data ini menggukan uji keseragaman dan uji kecukupan yang bertujuan untuk mengguji data yang ada pada perakitan Elevator, sehingga data tersebut termasuk dalam data seragam atau tidak serta untuk menentukan apakah data tersebut telah mencukupi atau tidak. Berikut merupakan contoh hasil perhitungan keseragaman data:

Tabel 4.2 Perakitan Motor Dengan Machine beam

\begin{tabular}{|c|c|c|c|c|c|c|c|c|c|}
\hline Sub grup & $\mathbf{x l}$ & $\mathrm{X} 2$ & $\mathrm{x} 3$ & $\mathrm{X} 4$ & X5 & $\Sigma \mathbf{i}$ & $\sum^{\overline{x i}}$ & $\sum \overline{x i}$ & $\Sigma(\bar{x}-\bar{x})$ \\
\hline 1 & 19 & 20 & 19 & 20 & 19 & 97 & 19.40 & \begin{tabular}{|l|l}
1883.00 \\
\end{tabular} & 129 \\
\hline 2 & 20 & 19 & 20 & 19 & 20 & 98 & 19.60 & 1922.00 & 122 \\
\hline 3 & 20 & 19 & 19 & 20 & 20 & 98 & 19.60 & 1922.00 & 122 \\
\hline & 293 & 58.60 & 5727.00 & 3.73 \\
\hline
\end{tabular}

Berikut perhitungan batas atas (BKA) dan batas bawah (BKB) di dapatkan hasil perhitungan sebagai berikut:

$\mathrm{BKA}=\overline{\bar{X}}+(\mathrm{Z}$ tabel $* \sigma x) \quad=19.53+(1.96 \times 0.30)=20.12$ $\mathrm{BKB}=\frac{X}{X}-(\mathrm{Z}$ tabel $* \sigma x) \quad=19.53-(1,96 \times 0.30)=18.95$

Perhitungan line balancing menggunakan metode ranked position weight yakni merupakan perhitungan berdasarkan dari jumlah $b=$ obot yang terbesar ke bobot yang terkecil pada proses perakitan elevator pada PT Hyundai Elevator Indonesia. Sehingga pembentukan jalur yang terbentuk dapat terlihat pada tabel berikut: 
Tabel 4.3 Pengurutan Pembentukan Jalur dan Bobot

\begin{tabular}{|c|c|c|c|}
\hline $\begin{array}{c}\text { No. } \\
\text { Operasi }\end{array}$ & $\begin{array}{c}\text { Operasi } \\
\text { Pendahulu }\end{array}$ & Jalur yang terbentuk & Bobot \\
\hline 1 & - & $1,2,3,4,5,8,9,12,13,14$ & 214.87 \\
\hline 2 & 1 & $2,3,4,5,8,9,12,13,14$ & 195.34 \\
\hline 3 & 2.1 & $3,4,5,8,9,12,13,14$ & 165.87 \\
\hline 6 & - & $6,7,8,9,12,13,14$ & 159.94 \\
\hline 4 & $1,2,3$ & $4,5,8,9,12,13,14$ & 137.40 \\
\hline 5 & $1,2,3,4$ & $5,8,9,12,13,14$ & 120.00 \\
\hline 7 & 6 & $7,8,9,12,13,14$ & 111.47 \\
\hline 8 & 6,7 & $8,9,12,13,14$ & 92.00 \\
\hline 10 & - & $10,11,12,13,14$ & 72.00 \\
\hline 11 & 10 & $11,12,13,14$ & 56.53 \\
\hline 9 & $6,7,8$ & $9,12,13,14$ & 52.47 \\
\hline 12 & 10.11 & $12,13,14$ & 38.00 \\
\hline 13 & $10,11,12$ & 13,14 & 20.53 \\
\hline 14 & $10,11,12,13$ & 14 & 0.00 \\
\hline
\end{tabular}

Pada metode ranked position weight di dapatkan hasil balanced delaynya sebagai berikut:

$$
\begin{aligned}
\mathrm{BD} & =\frac{\boldsymbol{K} \cdot C T-\sum W B}{\boldsymbol{k} \cdot C T} \times 100 \% \\
\mathrm{BD} & =\frac{(\mathbf{3} * \mathbf{1 5 5 . 5 1})-\mathbf{4 2 1 . 8 7}}{\mathbf{3} * \mathbf{1 5 5 . 5 1}}=\frac{44.65}{\mathbf{4 6 6 . 5 3}} \\
& =10 \%
\end{aligned}
$$

Sedangkan untuk delay time nya didapatkan hasil dengan menggunakan metode ini adalah sebagai berikut:

$$
\begin{aligned}
\text { DT } & =\text { K.ST. } \max -\sum_{i=1}^{k} S T i ; \text { DT } \\
& =\left(\left(3^{*} 155.51\right)-(155.51+147.25+119.11)\right) \\
& =466.525-421.87=44.65 \mathrm{~m}
\end{aligned}
$$

Efesiensi $=100 \%-\mathrm{BD}=100 \%-10 \%=90 \%$

Smooting indeks menunjukkan kelancaran relative keseimbangan lini didapatkan hasil sebagai berikut:

Tabel 4.4 Perhitungan Smoothing Indeks RPW

\begin{tabular}{|c|c|c|c|c|}
\hline Stasiun & ST MAX & ST K & ST MAX - STK & $(\text { STM - STK })^{2}$ \\
\hline 1 & 160.00 & 147.25 & 12.75 & 162.56 \\
\hline 2 & 160.00 & 155.51 & 4.49 & 20.17 \\
\hline 3 & 160.00 & 119.11 & 40.89 & 1671.63 \\
\hline \multicolumn{5}{|c|}{ Jumlah } \\
\hline
\end{tabular}

Smooting indeks $=S \mathbf{S I}=\sqrt{\sum_{\mathrm{i}=1}^{\mathrm{K}}\left(\mathrm{STi}_{\text {maks }}-\mathrm{STi}\right)^{2 \mid}}$

$$
=\sqrt{1854.37}
$$

$$
=43 \text { menit. }
$$

Sedangkan perhitungan line balancing dengan menggunakan Metode Kill Bridge Weston Heuristic yaitu metode yang membobotkan ukuran terkecil dengan jumlah elemen nya dan di urutkan dari jumlah elemen terke-

\begin{tabular}{|c|c|c|c|c|c|}
\hline Stasiun & No & Nama Elemen & $\underset{\text { (menit) }}{\text { WS }}$ & $\begin{array}{c}\text { Wb } \\
\text { (menit) }\end{array}$ & $\begin{array}{c}\text { Waktu } \\
\text { St } \\
\text { (menit) }\end{array}$ \\
\hline \multirow{4}{*}{1} & 1 & $\begin{array}{l}\text { Perakitan Motor Dengan Machine } \\
\text { Beam. }\end{array}$ & 19.53 & 30.27 & \multirow{4}{*}{147.25} \\
\hline & 2 & $\begin{array}{l}\text { Perakitan Motor Dengan Machine } \\
\text { Beam dan Traction Machine. }\end{array}$ & 29.47 & 45.68 & \\
\hline & 3 & $\begin{array}{l}\text { Perakitan motor Dengan Machine } \\
\text { Beam, Traction, dan Deflector } \\
\text { sheave. }\end{array}$ & 28.47 & 44.13 & \\
\hline & 4 & $\begin{array}{l}\text { Perakitan motor Dengan Machine } \\
\text { Beam, Traction, Deflector Sheave, } \\
\text { Control Panel. }\end{array}$ & 17.53 & 27.17 & \\
\hline \multirow{3}{*}{2} & 5 & $\begin{array}{l}\text { Perakitan motor Dengan Machine } \\
\text { Beam, Traction, Deflector Sheave, } \\
\text { Control Panel Dan Overspeed } \\
\text { Governer. }\end{array}$ & 27.53 & 34.14 & \multirow{3}{*}{136.40} \\
\hline & 6 & $\begin{array}{l}\text { Perakitan Car Door Dengan Door } \\
\text { safety device. }\end{array}$ & 48.47 & 60.10 & \\
\hline & 10 & $\begin{array}{l}\text { Perakitan Counterweight dan } \\
\text { counterweight guid rail. }\end{array}$ & 15.47 & 19.18 & \\
\hline \multirow{8}{*}{3} & 11 & $\begin{array}{l}\text { Perakitan Counterweight, } \\
\text { counterweight guid rail dan Guid } \\
\text { Roller. }\end{array}$ & 18.53 & 22.98 & \multirow{7}{*}{138.22} \\
\hline & 7 & $\begin{array}{l}\text { Perakitan car Door Dengan Door } \\
\text { safety device dan Door operator. }\end{array}$ & 19.47 & 24.14 & \\
\hline & 9 & $\begin{array}{l}\text { Perakitan Bagian Atas dan Lift } \\
\text { Dengan Car Guide Roller. }\end{array}$ & 39.53 & 49.02 & \\
\hline & 8 & $\begin{array}{l}\text { Perakitan Bagian Atas dan Lift } \\
\text { Dengan Car Guide Rail. }\end{array}$ & 14.47 & 17.94 & \\
\hline & 12 & $\begin{array}{l}\text { Perakitan lift dan counterweight } \\
\text { dengan Bagian Atas. }\end{array}$ & 17.47 & 21.66 & \\
\hline & 13 & $\begin{array}{l}\text { Perakitan lift dan counterweight } \\
\text { dengan Car Guide Rail Bracket. }\end{array}$ & 20.53 & 25.46 & \\
\hline & 14 & Produk lift & 0.00 & 0.00 & \\
\hline & & TOTAL & 0 & 421.87 & \\
\hline
\end{tabular}
cil ke jumlah elemen yang besar. Sehingga di dapatkan data sebagai berikut:

Tabel 4.5 Pengurutan Data

\begin{tabular}{|c|c|c|}
\hline $\begin{array}{c}\text { No. } \\
\text { Operasi }\end{array}$ & Operasi Pendahulu & $\begin{array}{c}\text { Jumlah } \\
\text { Elemen }\end{array}$ \\
\hline 1 & - & - \\
\hline 6 & - & - \\
\hline 10 & - & - \\
\hline 2 & 1 & 1 \\
\hline 7 & 6 & 1 \\
\hline 11 & 10 & 1 \\
\hline 3 & $1,2,3$ & 2 \\
\hline 4 & $1,2,3,4$ & 3 \\
\hline 5 & $1,2,3,4,5,6,7$ & 4 \\
\hline 8 & $1,2,3,4,5,6,7,8$ & 7 \\
\hline 9 & $1,2,3,4,5,6,7,8,9,10,11$ & 8 \\
\hline 12 & $1,2,3,4,5,6,7,8,9,10,11,12$ & 12 \\
\hline 13 & $1,2,3,4,5,6,7,8,9,10,11,12,13$ & 13 \\
\hline 14 & & \\
\hline
\end{tabular}

Setelah pengurutan elemen terkecil ke besar, pengolahan data sbb:

Tabel 4.6 Tabel Alokasi Perakitan Elevator

Pada metode kill bridge - weston heuristic didapatkan hasil perhitungan balanced delay-nya sebagai berikut: 


$$
\begin{aligned}
\mathrm{BD} & =\frac{K \cdot C T-\sum W B}{K \cdot C T} \times 100 \% \\
\mathrm{BD} & =\frac{(3 * 147.25)-422.87}{3 * 147.25}=\frac{19.88}{441.75} \\
& =4 \%
\end{aligned}
$$

Sedangkan untuk Delay Time nya di dapatkan dengan hasil sebagai berikut:

$\mathrm{DT}=\mathrm{K} . \mathrm{ST} . \max -\sum_{i=1}^{k} S T i$

$$
\begin{aligned}
\text { DT } & =((3 * 147.25)-(147.25+136.40+138.22)) \\
& =441.87-421.87=19.88 \text { menit }
\end{aligned}
$$

Sedangkan efesiensi yang diperoleh pada perhitungan line balancing ini dengan menggunakan metode di atas di hasilkan tingkat efisiensi sebagai berikut:

Effisiensi $=100 \%-\mathrm{BD}=100 \%-4 \%=96 \%$

Perhitungan Smoothing Indeks pada metode kill bridge - Weston heuristic ini dapat di lihat pada lampiran. Untuk hasil yang didapatkan dengan menggunakan smoothing indeks ini sebagai berikut:

Tabel 4.7 Perhitungan Smoothing Indeks KWH

\begin{tabular}{|c|c|c|c|c|}
\hline Stasiun & ST MAX & ST K & ST MAX - ST K & (STM - STK) $^{2}$ \\
\hline 1 & 160.00 & 147.25 & 12.75 & 162.56 \\
\hline 2 & 160.00 & 136.40 & 23.60 & 556.96 \\
\hline 3 & 160.00 & 138.22 & 21.78 & 474.25 \\
\hline \multicolumn{4}{|c|}{ JUMLAH } & 1193.77 \\
\hline
\end{tabular}

Smoothing indeks $=$

$$
\begin{aligned}
S I & =\sqrt{\sum_{i=1}^{K}\left(S T i i_{\text {maks }}-S T i\right)^{2 \mid}} \\
& =\sqrt{1193.77}=35 \text { menit. }
\end{aligned}
$$

\section{Pembahasan dan Analisis}

Pada pembahasan ini pengumpulan data dengan menggunakan uji kecukupan dan uji keseragaman untuk melihat data tersebut sudah seragam atau valid sehingga tidak adanya data yang melebihi data dari batas atas dan batas bawah, sedangkan uji kecukupan data untuk mengetahui data tersebut sudah mencukupi dari data keseluruhan pada tabel di atas data tersebut sudah seragam dan sudah mencukupi sehingga tidak memerlukan pengumpulan data, presidence diagram untuk mengetahui tingkat efesiensi lintasan perakitan dengan menggunakan lintasan pada PT Hyundai Elevator Indonesia sebanyak enam lini. Pada pengolahan data dengan menggunakan waktu baku di dapatkan jumlah lini sebanyak 3 lini dengan perhitungan sebagai berikut:

$$
\begin{aligned}
& \text { Jumlah stasiun }=\frac{\text { Total waktu baku }}{\text { waktusiklus terbesar }} \\
& \mathrm{N}=\frac{421.87}{160.00}=2,64=3 \mathrm{lini}
\end{aligned}
$$

Dibulatkan menjadi 3 lini karena dalam pembentukan lintasan perakitan elevator.

Anlisis:

\begin{tabular}{|c|c|c|c|c|c|}
\hline No & Kriteria & $\begin{array}{c}\text { Kondisi Awal } \\
\text { Perusahaan } \\
2015\end{array}$ & $\begin{array}{l}\text { Metode } \\
\text { RPW }\end{array}$ & $\begin{array}{c}\text { Metode } \\
\text { KWH }\end{array}$ & $\begin{array}{c}\text { Metode } \\
\text { RA }\end{array}$ \\
\hline 1 & Jumlah stasiun kerja & 6 & 3 & 3 & 3 \\
\hline 2 & Delay time (menit) & 65.81 & 44.65 & 19.88 & 56.04 \\
\hline 3 & Balance delay $(\%)$ & $45 \%$ & $10 \%$ & $4 \%$ & $12 \%$ \\
\hline 4 & Efisiensi lintasan (\%) & $55 \%$ & $90 \%$ & $96 \%$ & $88 \%$ \\
\hline 5 & Smoothing indeks (menit) & 55 & 43 & 35 & 46 \\
\hline
\end{tabular}

Berdasarkan dari metode diatas dapat diketahui bahwa ketiga metode tersebut memiliki hasil kapasitas yang berbeda-beda sehingga pada tabel di bawah ini dapat dilihat perbandingan ketiga mode tersebut pada tabel di bawah ini:

Tabel 4.8 perbandingan kondisi awal perusahaan dengan tiga metode

\section{SIMPULAN DAN SARAN}

1. Simpulan

Berdasarkan dari penelitian diatas dapat di simpulkan bahwa metode yang tepat untuk meningkatkan efisiensi lintasan pada perakitan elevator di PT Hyundai Elevator Indonesia dengan menggunakan metode kill bridge Weston heuristic (KWH), hal ini dapat dilihat dengan efisiensi lintasan sebelum dilakukan perbaikan lintasan pada tahun 2015 sebesar 55\% sedangkan setelah dilakukan perbaikan dengan menggunakan metode kill - bridge Weston heuristic (KWH), efisiensi lintasan perakitannya menjadi meningkat sebesar $41 \%$ menjadi $96 \%$ dari kondisi semula.

Sebelum dilakukan perbaikan lintasan pada perakitan elevator pada PT Hyundai Elevator Indonesia bottle neck nya sebesar $45 \%$ atau sebesar 65.81menit, sedangkan smoothing indeks nya sebesar 55 menit. Setelah dilakukan perbaikan dengan metode yang tepat yakni metode kill - bridge Weston heuristic (KWH), terjadi penurunan bottle 
neck sebesar $41 \%$ atau 45.93 menit dari kondisi semula menjadi $4 \%$ atau 19.88 menit. Sedangkan smoothing indeks nya menurun sebesar 20 menit dari kondisi semula menjadi 35 menit.

\section{Saran}

Perakitan elevator pada perusahaan PT. Hyundai Elevator Indonesia ini prosesnya memakan waktu yang lama, sehingga terjadi penumpukan pada proses perakitan elevator dan ketik efektifan waktu dalam perakitan tersebut untuk mengurangi dampak perkitan tersebut sebagai saran yang tepat untuk mengurangi penumpukan dan efisiensi waktu dengan memperbaiki lintasan pada perakitan PT. Hyundai Elevator Indonesia, yang telah diamati dengan menggunakan metode kill bridge Weston heuristic (KWH) tersebut sehingga dapat mempercepat efektifitas pada proses perakitan dan mengurangi penumpikan pada proses tersebut

\section{DAFTAR PUSTAKA}

Baroto, Teguh. 2002. Perencanaan dan Pengendalian Produksi, Jakarta: Ghalia Indonesia.
Ginting, Rosnani. 2007. Sistem produksi, Yogyakarta: Graha Ilmu.

Gaspersz, Vincencent. 2004. Production Planning and inventory Control Berdasarkan Pendekatan Terintegrasi MRP II dan JIT Menuju Manufacturing 21, Jakarta: PT. Gramedia Pustaka Utama.

Kusuma, Hendra. 2001. Manajemen Produksi-Perencanaan dan Pengendalian Produksi, Jakarta: Andi offset.

Liker, jeffry K. 2006. The Toyota Way - 14 Prinsip Manajemen Dari Perusahaan Manufaktur Terhebat Di Dunia, Jakarta: Erlangga. Bandung.

Purnomo, Hari. 2004. Pengantar Teknik Industri. Yogyakarta: Graha Ilmu. Sutalaksana, Iftikar Z. 2006. Teknik Perancangan Sistem Kerja, Bandung: ITB

Wignjosoebroto, Sritomo. 2008. Ergonomi Study Gerakan dan Waktu, Surabaya: Guna widya. 